After therapy, 7 patients had regression of symptoms and 1 patient had a permanent neurological impairment.

Conclusion: Multilevel spondylodiscitis involving non-contiguous spine segments is rare. Although atypical organisms are generally held to be responsible, the common bacteria such as Streptococcus B or Staphylococcus aureus should not be overlooked.

REFERENCES:

[1] Zimmerli W. Clinical practice.Vertebral osteomyelitis. N Engl J Med 2010 Mar;362(11):1022-9.

[2] Cottle L, Riordan T. Infectious spondylodiscitis. J Infect 2008; 56(June (6)):401-12

Disclosure of Interests: None declared

DOI: 10.1136/annrheumdis-2021-eular.3190

\section{POS1278 THE PREVALENCE AND CLINICAL SIGNIFICANCE OF ULTRASONOGRAPHIC FINDINGS OF DISTAL MEDIAL HAMSTRING TENDONS IN PATIENTS WITH POSTEROMEDIAL KNEE PAIN}

H. Saad ${ }^{1}$, Y. Gazar ${ }^{1}$, S. Ghanem ${ }^{1}$, A. Maaty ${ }^{2,3} .{ }^{1}$ Al-Azhar University, Cairo, Egypt, Rheumatology and Rehabilitation, Cairo, Egypt; ${ }^{2}$ Faculty of Medicine, Suez Canal University, Ismailia, Egypt, Physical Medicine, Rheumatology, and Rehabilitation, Ismailia, Egypt; ${ }^{3}$ Armed Forces Center of Health Rehabilitation, Taif, Saudi Arabia, Physical Medicine and Rehabilitation, Taif, Saudi Arabia

Background: Periarticular abnormalities are common ultrasonographic (U/S) findings in individuals with knee pain. Incidental U/S observations, including thickening of the distal hamstring tendons, require explanations for their clinical importance. Tendon thickness may be a good indicator of tendinopathy and tendon dysfunction. Also, it is uncertain whether these tendon changes are correlated with knee pain or not?

Objectives: The aim of this study was to determine U/S findings of distal medial hamstring tendons in patients with posteromedial (PM) knee pain and assess the diagnostic values of tendon thickness in predicting tendinopathy.

Methods: We studied distal medial hamstring tendons (semimembranosus [SM] and semitendinosus [ST]) of 104 patients (104 knees) with non-traumatic unilateral PM knee pain and 118 healthy controls (236 knees). U/S evaluations included tendon thickness, echogenicity, the presence of intrasubstance tears, calcification, and vascularity.

Results: The mean age (standard deviation) of the patients and control groups were 51.7 (10.4) years and 49.8 (9.9) years, respectively. The mean visual analogue scale (VAS) for pain among patients was 5.1 and $58.6 \%$ of them located the pain at medial joint line. The studied patients had significantly higher mean SM thickness $(7.17 \mathrm{~mm}$ vs. $5.46 \mathrm{~mm}$, respectively) and ST thickness $(3.93 \mathrm{~mm}$ vs. $3.45 \mathrm{~mm}$, respectively) than the controls. U/S abnormalities among patients were hypoechogenicity $(62.5 \%)$, intrasubstance tears $(31.7 \%)$, loss of fibrillar pattern (23.1\%), Baker cyst $(20.2 \%)$, calcification (18.3\%), Anserine bursitis (11.5\%), and neovascularization $(6.7 \%)$. We found significant correlations between tendon thickness and VAS $(r=0.752, p=0.004)$, and pain location $(r=0.680, p=0.008)$. SM thickness had higher accuracy to predict tendinopathy than ST thickness ( $80.6 \%$ vs. $68.9 \%$, respectively).

Table 1. Diagnostic values of tendon thickness in predicting tendinopathy.

\begin{tabular}{lccccccc}
\hline Tendons & Cutoff & Sensitivity & Specificity & +PV & -PV & Accuracy & AUC \\
\hline SM & $>6.6$ & 70.2 & 89.8 & 85.7 & 76.8 & 80.6 & 0.835 \\
ST & $>3.7$ & 56.7 & 79.6 & 71.1 & 67.6 & 68.9 & 0.696 \\
\hline
\end{tabular}

SM: semimembranosus, ST: semitendinosus, $+P V$ : positive predictive value, $-P V$ : negative predictive value, AUC: area under curve.

Conclusion: U/S changes are frequently present in patients with PM knee pain. Tendon thickness is an accurate predictor of tendinopathy. These findings suggest that U/S screening of all individuals with PM knee pain is a useful tool for improving patients' outcomes and decreasing tendon-related disability.

Disclosure of Interests: None declared

DOI: 10.1136/annrheumdis-2021-eular.3233

\section{POS1279 ADVERSE DRUG REACTIONS IN TUBERCULOSIS AND MANAGEMENT}

R. Grassa ${ }^{1}$, N. El Amri ${ }^{1}$, S. Lataoui ${ }^{1}$, O. Jomaa ${ }^{1}$, H. Zeglaoui ${ }^{1}$, K. Baccouche ${ }^{1}$, E. Bouajina ${ }^{1} .{ }^{1}$ Farhat Hached Hospital, Rheumathology, Sousse, Tunisia

Background: Around 10 million people worldwide contract tuberculosis (TB) every year. According to the World Health Organization (WHO), approximately one-quarter of the world's population is latently infected with Mycobacterium tuberculosis. Its treatment is extremely long and patients may experience a variety of adverse reactions.
Objectives: The aim of this study was to assess the different adverse drug reactions (ADR's) in patients treated with first-line anti-tubercular drugs.

Methods: This retrospective study included 45 cases of TB followed in the Rheu matology department of Farhat Hached hospital in Sousse, Tunisia, over a period of 22 years (1998-2020).

Results: The mean age was $52.2 \pm 17.72$ years [14-95 years]. These were 19 men (42.2\%) and 26 women (57.8\%). The different locations of tuberculosis were as follows: pulmonary for 5 patients $(11.1 \%)$, spinal for 26 patients $(57.8 \%)$, articular for one patient $(2.2 \%)$, urinary for two $(4.4 \%)$, and multifocal for 8 patients (17.8\%). An anti-tuberculosis treatment (based on quadrytherapy: Rifadine(R) Isoniazide(I), Pyrazinamide (Z) and Ethambutol (E)during 2 months, followed by biotherapy based on $(R)$ and $(I)$ was prescribed for an average duration of 10.85 months [6-24 months]. ADR's were observed in $53.33 \%$ of patients. Abdominal pain and nausea were detected in 5 cases (11.1\%). Hepatic cytolyse was noticed in 8 cases $(17.8 \%)$ under $(R)$. Cholestatic hepatitis occurred in 9 cases $(20 \%)$ under (R). Asymptomatic Hyperuricemia was detected in 15 cases (33.3\%) with $(E)$. Two cases of toxiderma were detected: the first under (E) and the second under $(E)+(Z)$. Ethambutol was responsible for a case of DRESS syndrome and a case of drug-induced hepatitis. One case of hemolytic anemia had occurred under $(\mathrm{R})$. A sensorineural hearing loss was noted under streptomycin in one case. No fatal side effects were observed. These ADR's were reversible in al cases.

Conclusion: The treatment of TB can cause a variety of ADRs'. Early recognition by active surveillance and appropriate management of these ADRs' might improve adherence and treatment success.

\section{REFERENCES:}

[1] Prasad, R., Singh, A., \& Gupta, N. Adverse drug reactions in tuberculosis and management. Indian Journal of Tuberculosis, 66(4), 520-532 (2019).

Disclosure of Interests: None declared

DOI: 10.1136/annrheumdis-2021-eular.3273

\section{POS1280 SPINAL LOCATION OF TUBERCULOSIS: WHAT HAS CHANGED OVER THE LAST YEARS?}

S. Boussaid ${ }^{1}$, M. Mrabet ${ }^{1}$, S. Jemmali ${ }^{1}$, H. Sahli ${ }^{1}$, H. Ajlani ${ }^{1}$, E. Cheour ${ }^{1}$, S. Rekik ${ }^{1}$, M. Elleuch ${ }^{1}{ }^{1}$ Rabta Hospital, Rheumatology, Tunis, Tunisia

Background: Tuberculosis (TB) is no longer a disease limited to developing nations and is still a major cause of significant morbidity and mortality worldwide. It can affect the different parts of the spine.

Objectives: The aim of this study was to determine the preferred spinal location of TB.

Methods: We conduct a retrospective and descriptive study in a single rheumatology department. Data were collected from observations of patients hospitalized in the past 20 years $(2000-2020)$ who have been diagnosed with tuberculous spondylodiscitis (TS)

Results: Fifty-two patients were included (37F/15M). Their mean age was 55.21 years \pm 17.79 [19-91]. TS was more frequently unifocal $(75 \%)$ than multifocal $(25 \%)$. Lumbar spine involvement was the most common (57.7\%) and more frequent in women $(63.3 \%)$ but with no statistically significant difference $(p=0.2)$. Other localizations were described such as: dorso-lumbar (21.2\%), dorsal (15.4\%), lumbosacral $(3.8 \%)$ and cervical (1.9\%). Lumbar pain was present in 34 patients $(65.4 \%)$ and 29 patients $(55.8 \%)$ suffered from segmental lumbar stiffness. Imaging was contributive by showing the vertebral location using standard X-rays, computed tomography and magnetic resonance imaging. Disc pinch, erosion of vertebral plateaus and vertebral collapse were the major signs $(82.7 \%, 65.4 \%$ and $67.3 \%$, respectively).

Conclusion: TS is a rare but serious clinical condition which may lead to severe deformity and early or late neurological complications. Spinal involvement is often unifocal and mostly diagnosed with lumbar pain or stiffness. Multifocal forms, touching several parts of the spine, however remain rare. Our findings remain consistent with those of the literature.

Disclosure of Interests: None declared

DOI: 10.1136/annrheumdis-2021-eular 3365

\section{POS1281 \\ HOW DOES OBESITY INFLUENCE THE FEATURES OF KNEE OSTEOARTHRITIS?}

H. Hachfi ${ }^{1}$, D. Khalifa ${ }^{1}$, M. Brahem ${ }^{1}$, N. Ben Chekaya ${ }^{1}$, M. Younes ${ }^{1}{ }^{1}$ Taher Sfar Hospital, Rheumatology, Mahdia, Tunisia

Background: Knee osteoarthritis and obesity are both major health problems. It is now admitted that the prevalence of knee osteoarthritis gets higher with obesity and that weight loss helps knee function and allows patients to avoid surgery. Objectives: The aim of this study was to study the influence of obesity on knee osteoarthritis features.

Methods: A cross-sectional study was conducted in the university hospital Taher Sfar of Tunisia over a period of 6 months. Patients who had knee osteoarthritis confirmed by radiographs were included. Sociodemographic, clinical, radiological and therapeutic data were collected from medical records and visits. Obesity was 
defined by a body mass index $(\mathrm{BMI}) \geq 30$. Functional impairment was assessed by the Womac index and Lequesne index.

Results: The study included 186 patients. There were 31 males and 155 femmes. The mean age was $60 \pm 10$ years. The percentage of obese patients was $53,8 \%$. The mean age was similar in both groups obese and non obese. There were more women in the obese group compared to the non obese group $(\mathrm{p}=0.0001)$, more patients who had diabetes mellitus and dyslipidemia ( $p=0.002$ ). Non-obese patients had a shorter duration of symptoms with no statistical significance $(p=0.151)$. Obese patients had more involvement of both knees $(p<0.0001)$. Obesity did not have an impact on pain severity. Severity of radiological images $(p=0,0001)$ were more frequent in obese patients. Functional impairment was similar in both groups. However, the percentage of patients having a very important functional impairment with Lequesne index was higher in obese patients $(p<0.029)$. Obese patients also needed more physical therapy sessions $(p=0.035)$.

Conclusion: Knee osteoarthritis in obese patients is characterized with the femlae gender predominance, bilateral knee involvement, and a more severe images on radiographs. Thus the need for better control of weight and the importance of physical activity.

REFERENCES:

[1] Coggon D, Reading I, Croft P, et al. Knee osteoarthritis and obesity. Int J Obes Relat Metab Disord J Int Assoc Study Obes 2001; 25: 622-627.

Disclosure of Interests: None declared

DOI: 10.1136/annrheumdis-2021-eular.3602

\section{POS1282 VERIFICATION OF MANIFESTATIONS OF SARCOPENIA IN OBESE PATIENTS WITH THREE METHODS FOR BODY COMPOSITION ASSESSMENT}

V. Vasileva ${ }^{1}$, L. Marchenkova2, V. Sergeev2. ${ }^{1}$ National Medical Center for Rehabilitation and Balneology, Department of Somatic Rehabilitation, Reproductive Health and Active Longevity, Moscow, Russian Federation; ${ }^{1}$ National Medical Center for Rehabilitation and Balneology, Department of Somatic Rehabilitation, Reproductive Health and Active Longevity, Moscow, Russian Federation

Background: With new technologies for body composition assessment determining changes learn, muscle and fat mass. Prevention of sarcopenic obesity is timely detection of decrease.

Objectives: Aim of the study was to compare the effectiveness of three methods of body composition assessment such as bioimpedans analysis (BIA), air-replacement bodyplatismography (BodPod) and Dual X-ray absorptiometry Total body program (DXA Total Body) in the verification of reducing of skeletal muscle mass as sign of sarcopenic obesity in obese patients.

Methods: The study group included 95 patients aged 21-69 y.o. (average age $53,9 \pm 11,05$ years) with $\mathrm{BMl} \geq 30.0 \mathrm{~kg} / \mathrm{m} 2$. The control group included 37 patients aged $37-69$ y.o (average age $50,73 \pm 10,6$ years) of the same age without obesity with BMI 20.0-29.9 kg/m2. Body composition was tested using BIA, BodPod and DXA with calculating fat, lean and skeletal muscles mass $(\mathrm{kg})$ and \% in all the patients.

Results: According to BIA the groups differ only in fat mass (FM) $42.75(4.8 ; 6.3)$ vs. $33.15(28.4 ; 35.5) \mathrm{kg} ; \mathrm{p}=0.036$ and did not differ ( $p>0.05$ ) in lean (LM), skeletal muscle mass (SMM) and in \% of FM and SMM. According to BodPod analyses groups differed in the FM $3.4[36.81 ; 69.94]$ vs $31.02[23.22 ; 38] \mathrm{kg}, \mathrm{p}=0.007, \%$ FM $45.4[42.1 ; 53.8]$ vs 37.7 [28.6;41.1], $p=0.003$ and $\%$ LM - 54.6 [46.2;57.9] vs 62.3 [58.9;71.4], $p=0.003$, but had statistically equivalent values of LM $55[49.48 ; 67.77]$ vs $40.36[33.12 ; 49.06]$ $\mathrm{kg}, \mathrm{p}=0.19$. According to DXA Total Body analyses statistically significant differences $(p<0.05)$ have been identified between the groups in FM and \% FM of the hands, feet, trunk, total body ( $p>0.05)$, but not in LM and \% LM $(p>0.05)$ (Table 1$)$.

Table 1. Effectiveness of three methods for body composition assessment

\begin{tabular}{lccc}
\hline INDICATORS & STUDY GROUP & CONTROL GROUP & $\mathbf{p}$ \\
\hline Weight $(\mathrm{kg})$ & $106[96 ; 122]$ & $80[77 ; 81]$ & 0.00251 \\
BMI $(\mathrm{kg} / \mathrm{m} 2)$ & $37.6[104 ; 124]$ & $26.8[24 ; 30]$ & 0.000000 \\
Bod Pod & & & \\
$\%$ fat mass & $45.4[42.1 ; 53.8]$ & $37.7[28.6 ; 41.1]$ & 0.003424 \\
$\%$ lean mass & $54.6[46.2 ; 57.9]$ & $62.3[58.9 ; 71.4]$ & 0.003424 \\
fat mass $(\mathrm{kg})$ & $43.4[36.81 ; 69.935]$ & $31.016[23.223 ; 38.004]$ & 0.006836 \\
lean mass $(\mathrm{kg})$ & $55.002[49.48 ; 67.77]$ & $40.359[33.122 ; 49.058]$ & 0.185377 \\
BIA & & & \\
fat mass $(\mathrm{kg})$ & $42.75[4.8 ; 6.3]$ & $33.150[28.4 ; 35.5]$ & 0.035771 \\
lean mass $(\mathrm{kg})$ & $59.5[53.95 ; 71.05]$ & $54.850[49.9 ; 62.6]$ & 0.458312 \\
skeletal muscle mass $(\mathrm{kg})$ & $27.9[23.9 ; 33.2]$ & $25.6[22 ; 29.3]$ & 0.701678 \\
skeletal muscle mass $(\%)$ & $45.3[43.3 ; 47.7]$ & $47.1[42.3 ; 48.1]$ & 0.415687 \\
DXA Total Body & & & \\
total body lean mass $(\mathrm{g})$ & $97276[86062 ; 109154]$ & $62628[57839 ; 85068]$ & 0.602523 \\
total body fat mass $(\mathrm{g})$ & $47030[39300 ; 56729]$ & $25652[22164 ; 36396]$ & 0.009796 \\
total body muscle mass $(\mathrm{g})$ & $49861[42793 ; 57088]$ & $36426[32273 ; 43341]$ & 0.973711 \\
\hline
\end{tabular}

Conclusion: From methods of body composition assessment, air-replacement bodyplatismography (BodPod) is the most sensitive in the verification of skeleta muscle mass reduction in obese patients. This method shows that patients with obesity have a significantly reduced muscle mass compared with normal weight or overweight subjects.

\section{REFERENCES:}

[1] L. A. Marchenkova, V. A. Vasileva, Motor and balance function disorders and possibilities of their correction in patients with obesity and metabolic syndrome // Lechashchiy vrach. 2019. № 4. S. 68.

[2] P. Corbeil, M. Simoheau, D. Rancourt, A. Tremblay, N. Teasdale, Increased risk for falling associated with obesity: mathematical modeling of postural control // IEEE Transactions on Neural Systems and Rechabilitation Enqineering. 2001; 9 (2): 126-136.

Disclosure of Interests: None declared

DOI: 10.1136/annrheumdis-2021-eular.3629

\section{POS1283 SPONDILODISCITIS WITHOUT DOCUMENTED GERM: WHAT THERAPEUTIC MANAGEMENT?}

R. Grassa ${ }^{1}$, N. El Amri ${ }^{1}$, K. Baccouche ${ }^{1}$, S. Lataoui ${ }^{1}$, H. Zeglaoui ${ }^{1}$, E. Bouajina ${ }^{1}$ ${ }^{1}$ Farhat Hached Hospital, Rheumathology, Sousse, Tunisia

Background: Spondylodiscitis (SD) is an infectious inflammation that affects the vertebrae, vertebral discs and adjacent structures. It may have a bacterial or non-bacterial etiology. Although analysis has improved and identification of pathogens is highly pursued, in one third of cases, no organism can be identified. Objectives: The objective of our work is to describe the epidemiological, clinica and evolutionary profile of SD with no germ identified and management.

Methods: This is a retrospective study including 37 cases of SD with no germ identified, collected in the Rheumatology Department of Farhat Hached hospital in Sousse, Tunisia over a period of 22 years (1998-2020).

Results: The mean age was 59.7 years [18-97 years]. These were 21 men (56.76 $\%)$ and 16 women (43.24\%).Spinal pain was the major symptom. The lumbar location was the most frequent in $56.76 \%$ of cases. It was a multifocal localization in $21.62 \%$. The imaging allowed the detection of para abscesses -vertebral in 43.24\%. An epiduritis was objectified in $54.05 \%$.CT-guided biopsy was performed in $59.46 \%$ and it was not conclusive. A bacteriological survey was carried out and came back negative. Spondylodiscitis was presumed to be tubercular and staphylococcal in respectively $62.16 \%$ and $18.92 \%$. The tuberculosis origin was retained in view of the chronic evolution, the multi-stage damage in the radiological assessment. While staphylococcal SD was retained due to the presence of cutaneous lesion and subacute evolution. Large-spectrum antibiotic therapy was initiated in the other cases.One case was initially considered to be staphylococca but with epidural and soft tissue extension tuberculosis was then considered to be the cause. The evolution after initiation of adequate antibiotic treatment was interspersed with neurological complications in one case of tuberculosis SD.

Conclusion: Our results show a higher frequency of presumed tuberculosis SD consider ing the endemicity of our country and the improvement under anti tuberculosis treatment REFERENCES:

[1] Cornett, C. A., and al. Bacterial Spine Infections in Adults. Journal of the American Academy of Orthopaedic Surgeons, 24(1), 11-18.(2016)

[2] Lener, S., and al Management of spinal infection: a review of the literature. Acta Neurochirurgica, 160(3), 487-496.(2018)

[3] Homagk, L., and al SponDT (Spondylodiscitis Diagnosis and Treatment) spondylodiscitis scoring system. Journal of Orthopaedic Surgery and Research, 14(1).(2019)

Disclosure of Interests: None declared

DOI: 10.1136/annrheumdis-2021-eular.3649

\section{\begin{tabular}{|l|l}
\hline POS1284 FASCIAL ULTRASOUND: THE CONTEXT FOR DRY \\
\hline
\end{tabular} NEEDLING TRIGGER POINTS IN TREATMENT OF MYOFASCIAL PAIN, POSTURAL IMBALANCE}

R. Bubnov ${ }^{1}$, L. Kalika ${ }^{2}{ }^{1}$ Clinical Hospital "Pheophania”, Ultrasound, Kyiv, Ukraine; ${ }^{2}$ NYDNRehab: Physical Therapy Clinic \& Chiropractic NYC Rehabilitation, New York, United States of America

Background: Muscles and fascia are the major source of pain in rheumatic diseases. Dry needling under ultrasound guidance (DN-US) is a crucial therapeutic approach to treat muscle pain [1,2], the definition 'myo-fascial' calls for searching trigger points (TrPs) in fascia to improve the treatment effectiveness.

Objectives: Aim was to evaluate the relevance of fascial ultrasound for DN-US in myo-fascial pain.

Methods: We included 36 patients (21 females, 20-69 years old) with myofascial pain different localisations (low back, limbs, shoulder, neck pain), postural imbalance; did DN-US protocol according to R. Bubnov [1]: trigge points were identified according, fine (28G) steel needle DN-US was applied. Additionally considered fascial structures for detecting areas of abnormalities (hypervascularity, heterogeinity, hypomotility, adhesions) aka 'trigger points and potental nerve compression/irritation and did precise DN-US where appropriate.

Results: In all patients movement restored and pain decreaed after muscles $\mathrm{DN}$; in 30 patients additionally we detected and did successful DN-US the 